\title{
Investigation of Apoptotic Effects of Usnic Acid on Hepatocellular Carcinoma ${ }^{\dagger}$
}

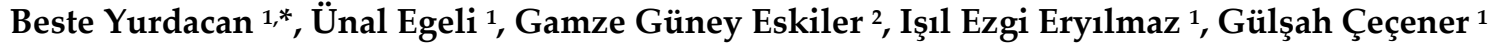 \\ and Berrin Tunca ${ }^{1}$ \\ 1 Medical Biology Department, Faculty of Medicine, Uludag University, Gorukle, Bursa 16059, Turkey \\ 2 Medical Biology Department, Faculty of Medicine, Sakarya University, Sakarya 54050, Turkey; \\ gguneyy@gmail.com \\ * Correspondence: besteyurdacan93@gmail.com; Tel.: +90-0224-295-41-60 \\ + Presented at the 2nd International Conference on Natural Products for Cancer Prevention and Therapy, \\ Kayseri, Turkey, 8-11 November 2017.
}

Published: 15 November 2017

\begin{abstract}
Hepatocellular carcinoma (HCC) ranks the sixth among common cancers in the world due to limited treatment option. In recent years, fungicides and lichen metabolites have gained importance in development of new generation chemotherapeutics. For this purpose, we aimed to investigate the cytotoxic and apoptotic effects of a lichen metabolite, usnic acid (UA), on HCC cells in the present study. After treatment with different concentrations $(6.25-100 \mu \mathrm{M})$ of UA for $48 \mathrm{~h}$, a significant decrease in the number of viable cells was determined in HCC cells. The HepG2 and SNU-449 cell viability decreased to $21.8 \%$ and $15.6 \%$ at the maximum concentration, respectively $(p<0.05)$. However cell viability ratio was $104.3 \%$ in HUVEC cells. Additionally, UA induced particularly late apoptosis in HCC cells in a dose-dependent manner. The percentage of apoptotic cells was significantly increased to $86.67 \%$ and $81.36 \%$ at $100 \mu$ M UA in HepG2 and SNU-449 cells, respectively. To confirm the apoptosis-inducing effect of UA, cells were stained with AO/EB and the morphological characteristic of apoptotic cell death were observed. In conclusion, UA displayed cytotoxic and apoptotic activity against human HCC cells without damaging control cells. Thus, we think that UA may be a suitable candidate as therapeutic agent for treatment of HCC.
\end{abstract}

Keywords: Hepatocellular carcinoma; usnic acid (UA); cytotoxicity; apoptosis

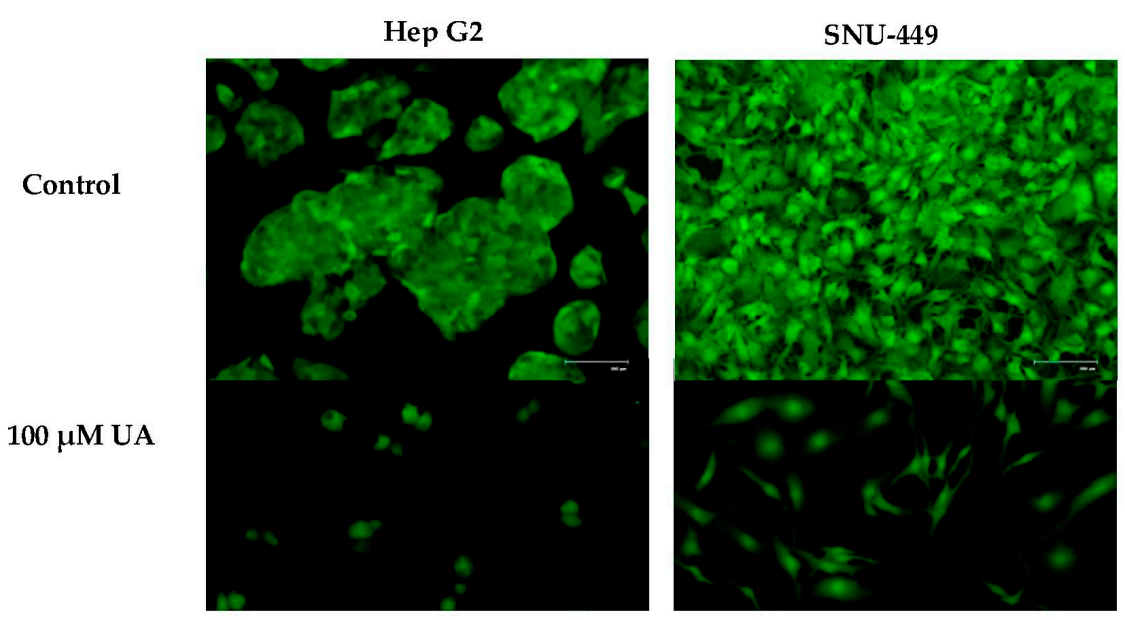

Figure 1. Morphological changes caused by UA in Hep G2 and SNU-449 cells. 
Acknowledgments: We thank to Mehmet Ozturk from Dokuz Eylul University, Faculty of Medicine, Basic Medical Sciences Department of Medical Biology, who kindly provided hepatocellular carcinoma cell lines for the study.

(C) 2017 by the authors. Licensee MDPI, Basel, Switzerland. This article is an open access article distributed under the terms and conditions of the Creative Commons Attribution (CC BY) license (http://creativecommons.org/licenses/by/4.0/). 